\title{
Improvement of the Teaching of Vocational Technical Education through Scientific Supervision \\ Anthony A. Akpan
}

\section{Abstract}

The purpose of this paper is to discuss how scientific supervision can be used to improve the teaching of vocationalTechnical Education. The early concept of scientific supervision has been replaced with a technology of instruction which involves the creation of curriculum materials in line with instructional technologists' demand for specification of objectives; measures that match objectives with evaluation and testing of learning sequences in both laboratory and field situation. This implies that in the absence of supervisors for schools, instructional materials should be developed for teachers of vocational-technical education to include objectives of instructions and provision for the means of attainment. The paper recommends the adoption of Competency-based Vocational Education (CBVE) and performance Testing.

\section{Introduction}

Teaching involves skills that are learned through participation and practice. The industrial education teacher is a teacher of two worlds: the world of the conventional classroom; for he has to posses the skills which every other teacher has to be able to teach the fundamentals of every task before proceeding to the laboratory. The second world is the world of the laboratory because he must be there to instruct and guide the students' production enterprises. It should be noted that the foremost aim of technical education is to 
"produce", which results in products and services. The need for a sound principle that can produce a powerful technical culture to guide technical teachers in their pedagogical behavior is the subject matter of this paper. It is observed in the teaching of technical education that the "body of knowledge" (technology and industry) is not satisfactorily treated. In most cases no mention is made of it; whereas the organizational concept is the industry producing 'goods and services' and technology answers the question; how do we do these things?

\section{The Concept of Scientific Supervision of Teaching:}

An underlying assumption of scientific supervision was that the efficiency of teachers would be increased through the guidance of a supervisor who would translate the aims and objectives of the school into terms which the teachers understand; this understanding would make the teachers accept the aims and objectives. It was also assumed that supervisors would help teachers adopt the curriculum in the light of community and individual factors and would analyze teaching; judge the quality of the results.

Scientific supervision is concerned with finding out why some people are more effective teachers than others. Since the central dimension in the supervision of teaching is to make teachers more effective, such information is vital and can be sued to help other teachers to be effective in their teaching career. Research in teacher effectiveness has not been very prominent in Nigeria but as McNeil (1982:40) observed, the search for effective teaching methods and teachers is like the search for the Holy Grail. 
Improvement of the Teaching of Vocational Ed....

Although we know that not all teachers can be successful teachers because teaching is an art, yet educators have the responsibility to search for ways and means of making teachers more effective; and scientific supervision is probably the best way to achieve it.

McNeil (1982) observed that by 1930, there was that difficulty of separating scientific supervision from the scientific study of education. He explained that data generated from early investigation (experimental and statistical) for knowledge of optimum methods to be employed by teachers were deemed inadequate. Instead supervisors were to be familiar with the broad range of educational research and to use this knowledge in the appraisal, training, and improvement of teachers. Supervisors were to draw implications from research undertaken by educational psychologist interested in mental measurement, individual differences, and the psychology of learning. They were to construct, understand and use new types of test suggested by educational measurement experts; and they were to see that teachers formulated objectives in accordance with the curriculum experts' new techniques.

Between 1930 and 1950, the concept of scientific supervision changed from that of regarding research findings as fixed conclusions, formulated into a pattern for all to follow, to that of regarding such findings as data for sharpening observation and directing further thinking. Accordingly, the object of scientific supervision was the development of teachers who would attack their classroom problems scientifically, free from the control of tradition and activated by the spirit of inquiry. Supervisors and teachers together were to adopt an experimental attitude, trying out new procedures, and studying the effect of each newly introduced means of improvement until satisfactory results were attained.

About the period under reference, scientific supervision was viewed as an answer to the lack of clearly defined 
standards. This made it difficult to determine the best method used by the teachers and which teachers were doing the best work. Sergiovanni (1981) saw scientific supervisors as addressing two initial tasks.

- Guiding teachers in selection of methods and preparing and renewing teachers

- Supervisors themselves were to discover the best procedures for performing teaching task and to help teachers acquire these methods in order to ensure maximum students achievement.

Basic to this early concept of scientific supervision was the need for replacement for supervision that appeared to be personal and arbitrary. About that time (1930) in the United States teacher preparation and renewal were to be undertaken only after identifying the teacher's weaknesses by measuring the teacher's knowledge of subject matter, understanding of methods and teaching processes, ability to see teaching in academic and social perspective, endurance and energy, whereas in Nigeria, even though teaching is supervised yet teachers are not promoted from the outcome of the supervision but through years of service and additional qualification.

\section{A Technology of Instruction (Learning and Behavioural Theory)}

Behavioural Scientists like B. F. Skinner and R. M. Gagne postulated that effective teaching could best be made by applying psychological theories of learning and the application of the results of experiments involving controlled manipulation of specific factors. The development of teaching machines and programmed instruction became the vehicle of 
Improvement of the Teaching of Vocational Ed....

generating ideas about critical instructional variables which cannot be measured and quantified. Kerman (1979) explaining Skinner's design of teaching machines drew attention to the importance of such instructional variables as active covert responding, elicitation of covert responses, reinforcement, and knowledge of results. But the present thinking based on cognitive psychology is that human behaviour cannot be controlled and manipulated for specific results as is the case in physical and chemical sciences. Psychologist, such as Lumisdaine (1964) and Gagne (1967) who had been engaged in training research for the military in World War II, sought to develop an instructional technology by which a teacher could be aided and made more effective.

Lumsdaine stressed the need for controlled equipment showing the influence of specific factors that consistently influenced the outcomes of instructions. He then drew some of these conclusions;

$\checkmark$ Covert responding is less important in meaningful context learning than in rote learning.

$\checkmark$ That such responding is likely to be greatest with every young children and with difficult material

$\checkmark$ That there is value in prompting or cueing student responses in learning a procedural skill.

$\checkmark$ That learning may be enhanced by repetition, pacing, review, and opportunity to repeat missed items.

Lumisdaine then called for better definitions of variables and analysis of their interaction as well as empirical demonstration of the effect of these variables in particular instructional programmes.

These ideas have been criticized by Cognitive Psychologist who have shown that controlled equipment cannot work with human beings for no success has been recorded up to this moment. Ausubel (1968) is of the opinion 
that the most important single factor influencing learning is what the learner already knows. He called on teachers to ascertain this and teach the student accordingly.

Theories of learning beginning with the behaviourists to the cognitive psychologists' are not without criticisms. Novak's (1979) criticism of the behaviourist theory could be seen in these few lines of thought:

Unhappily, behaviourist doctrine continues to flourish in education, largely without awareness of their inherent peripheralist philosophy, and thus they crowded educational niches that might be utilized more fruitfully by other concepts. Kenneth strike has examined this problem and has criticized the farfetched extension of peripheralism into social planning in Skinner's Beyong Freedom and Dignity.

The "discovery approach in cognitive psychology by Wolfagang was criticized. Other cognitive psychologist like Jerome Bruner who demonstrated that pupils can learn more effectively when they develop their own mediators: David P. Ausubel who showed how advance organizers serve as mediating links were put together and criticized by Skinner (1971) in his reaction to "discovery approach" thus:

It is foolish and impossible to expect students who live in a technological society to discover everything for themselves, particularly because the discovery approach is inefficient and time consuming. Furthermore, interpersonal problems may arise if one or two pupils routinely make most of the discoveries. Finally, parents and school administrators may object if the impression is that students are expected to educate themselves (in Biechler, 1978) 
Improvement of the Teaching of Vocational Ed....

Gagne (1976) stressed the idea that achievement of the objective of an instructional programme may depend on whether or not the learner has attained the learning prerequisites to the task that the programme is designed to teach. Accordingly, the teacher would have to decide on the ultimate goal and determine the subskills necessary for the learner to progress smoothly to the goal, keeping in mind the methods and materials to be used. Knowing the components of a logical and hierarchical sequence and the use of this sequence in preparing diagnostic test to asses the learner's preparedness offers considerable possibility for improving instruction.

Here again, one is left to wander whether the thought pattern of all learners are logical, and whether a hierarchical sequencing of skills or tasks calls for a "top to bottom" or "bottom to top" approach. The theory of integrative reconciliation has proved Gagne's theory wrong. It is now believed that learning could proceed from complex to simple without prerequisite knowledge.

Garrol (1963) presented a conceptual model of the learning process that proposed that success of learning as a function of five elements:

$\checkmark \quad$ Aptitude - basic characteristics that influence the time sequence for one to attain mastery of a task.

$\checkmark \quad$ Intelligence - the ability to understand the task to be learned and the procedures to follow in learning the task.

$\checkmark \quad$ Perseverance - the amount of time during which one will engage in active learning of the task reflected in the pacing of instruction relative to the students capacity to profit from it.

$\checkmark \quad$ Quality of instruction - the degree to which elements of the task are presented, explained, and ordered. 
$\checkmark \quad$ Opportunity for Learning - the amount of time allowed for learning reflected in the pacing of instruction relative to the students capacity to profit.

While the first three elements reside in the learner, the latter two reside in the teaching.

The Technology of instruction emanating from the work of these behavioural scientists had great impact on both school practice and the conduct of research on teaching effectiveness. For example, in the United States of America, Government supported agencies such as Regional Laboratories for research and development, created curriculum materials that followed the technologist demand for specification of objectives; measures that match the objective to use in the evaluation: delineation of the component skills requisite for achievement of the objective; prototype of development and tryout; and testing of the learning sequences on both the laboratory and field situations to find out to what extent they attain the desired results.

The application of technology to the development of instructional products constitute an indirect form of supervision that is, product developers external to the classroom determine objectives of instructions and provide the means to attainment. Nigeria is adopting this technology, for example, the National Board for Technical Education (NBTE) curriculum has the objectives for every course spelt out and teachers are to follow these objectives strictly.

Although it has been more popular to focus on teachers as the way to effect instructional improvement, behavioural scientists with a product development orientation assumed that by improving materials, they would improve educational practice. Technology of instruction was not only applied in the 
Improvement of the Teaching of Vocational Ed....

development of products. Instructional procedures associated with mastery learning, personalized teaching (The Keller Plan 1974), individualized instruction, and other popular innovations are based on the concepts and work of the behavioural scientists.

Indeed one can make the case that present trends in competency - based vocational education and performance testing are dependent on the technologists' notions of specified objectives, criterion measure, and direct practice with important skills.

Criticism of learning theory as a basis of guiding teaching practice was forthcoming. Mekeachie (1974) attacked Skinner on programmed instruction as well as the laws of learning themselves as applied to human learning. He challenged the usefulness of the concept of reinforcement by citing incidents when children do less well in learning when materially rewarded, and the concept of knowledge of result by citing evidence showing that knowledge of results does not always produce better learning and that feedback and praise do not always lead to improvement.

\section{The Process - Product Paradigm}

Gage (1978) is a preventative proponent of an approach by which investigators search for teaching process (teacher behaviour and characteristics) that predict or cause student achievement and attitude. This approach is similar to that followed by Alfonso and Goldsberry (1982) in a prior era of criterion of effectiveness studies. This approach as carried out in the past is claimed to have failed to produce conclusive knowledge for a variety of reasons:

$\checkmark \quad$ Failure to control for the intervening events between teaching behaviour and outcomes.

$\checkmark \quad$ Failure to get the meaning behind teacher behavour. 
$\checkmark \quad$ Failure to attend to the variables that are unstable, but important in bringing about learning.

$\checkmark$ And failure to recognize that the relation between teacher's practice and results need only be better than chance.

Gage sees some ways of overcoming these failures and holds that the approach will lead to a scientists finding that will allow teachers to know that certain teachers behaviours are likely to have an effect on what students learn.

In as much as the number of variables referring to teacher behaviour, pupil behaviour, and classroom environment number in the hundreds, Gage recommends instructional treatments that combine teacher variables found to correlate with pupil achievements into combinations of components.

By testing the significance of combine results through an estimation of "nonchanceness" of a number of independent findings related to a process variable, Gage has been able to find effects that were masked in isolation. This situational technique is aimed to overcoming the failure to find significant correlation due to small sample size. After shifting several hundred variables in teacher behaviour, Gage developed a set of inferences as to how third grade teachers should work if they wish to maximize achievements in the basic skill. Most of these call for optimizing academic learning time.

$\checkmark$ Establish classroom rules that allow pupils to attend a personal and procedural need without having to check with the teacher.

$\checkmark$ Move around the room a lot, monitoring seatwork and attending to academic needs. 
Improvement of the Teaching of Vocational Ed....

$\checkmark$ When pupils work independently, ensure that assignments are interesting and worthwhile, yet easy enough to be completed without teacher direction.

$\checkmark$ Spend little time in giving directions and organizing the class.

$\checkmark$ Call on a child by name before asking questions to ensure that all have opportunity to respond.

Medley (1979) claims to have overcome other limitations of process - product research by summarizing the results of studies of teacher behaviour that used pupil gain after several months of instruction as the criterion of effectiveness. He concluded that the following three kinds of teacher behaviour have strong enough relationships to effectiveness that they can be considered dependable:

- Learning Environment - the effective teacher has a classroom that is orderly and psychologically supportive.

- Use of pupil time - the effective teacher devotes more time to academic activities with the class organized in one large group. Although effective teachers devote less time to pupil seatwork than ineffective ones, they supervise pupils engaged in seatwork more closely.

- Method of instruction - contrary to popular opinion teacher who use more low-level questions and whose pupil initiate fewer questions and get less feedback or additional amplification of their questions are associated with higher pupil gains.

Medley's research is consistent with the findings from a number of process-product researchers. For example, Rosinshine (1977) found that promising variables that showed the highest correlation with achievement are those related to content covered (opportunity to learn what is being tested) and task orientation or academic focus. 
The work of Beliner and other s (1994) at North West Laboratory for Educational Research and Development and the research work of Prophy and Evertson (1994) further support the values of teachers giving direct supervision to pupils in order to ensure academically engaged time.

\section{Innovation in Vocational Technical Education}

It has been seen that the development of instructional products constitute an indirect for $m$ of supervision. Again instructional procedures associated with mastery learning, personalized teaching, individualized instruction, competencybased vocational education and other popular innovations based on the concepts and work of the behavioural scientists are indirect form of scientific supervision.

One of these innovations in vocational-technical education is "Competency-Based Vocational Education" (CBVE). Blank (1980), provides ten reasons why CBVE is better than the traditional approach:

$\checkmark$ Students often vary in Ability and level of motivation

$\checkmark$ Training time can be shortened for some students

$\checkmark$ Needs of special learners can be met more effectively

$\checkmark$ Failures are reduced

$\checkmark$ The present educational system is out of step with the reality of the world in which we work and live

$\checkmark$ The CBVE approach allows us to hold proficiency constant and at high level and allows individual training time to vary

$\checkmark$ Students overwhelmingly prefer CBVE

$\checkmark$ The CBVE approach promotes greater accountability of students, instructors and the training programme

$\checkmark$ CBVE can result in better articulation among training institutions 
Improvement of the Teaching of Vocational Ed....

$\checkmark$ The world of work is basically task oriented.

\section{Summary and Conclusion}

Future scientific research into supervision will probably follow the direction of social research in general. This means that scientific supervision will be seen as only one among several analytical methods for improving instruction. Other forms of information and analysis, including the ordinary knowledge of supervisors and teachers, may be effective than the result of scientific enquiry. Ordinary knowledge is not won by the methods of science, but by common sense and thoughtful speculation. Such knowledge is highly fallible, but nevertheless, knowledge to anyone who takes it is a basis for action (Linblom and Cohen 1979).

\section{Recommendation}

Based on the findings of this paper, the following recommendations are made:

- Teachers should continue to give direct supervision to pupils in order to ensure academically engaged time.

- Teachers should endeavour to cover the content of what they have to teach pupil and test them out.

- Adaptation of instructional treatments that combine teachers variables found to correlate with pupil achievements.

- Teachers should ascertain that they teach students from what they already know.

- Instructional technology should only be seen as an aid for a more effective teaching and not as a means itself.

- Scientific supervision should be viewed as guiding teachers in selection of methods and preparing and renewing them. 


\section{References:}

Alfonso, R. J. \& Goldsberry, L. (1982). Colleagueship in Supervision Edited by T. J. Sergiovanni. In Supervision and Teaching. Alexander, Va. Association for Supervision and Curriculum Development. 30 (1) 90-107.

Ausubel, D. P. (1968). Educational Psychology: A Cognitive view. Educational Psychology. New York: Rinchart and Winston.

Berliner, D. C. and others (1994). Phase III of the Beginning

Teacher Evaluation Study. West Laboratory for Educational Research and Development.

Biehler, R. F. (1978). The Cognitive Discovery of Learning Psychology Applied to Teaching. Dallas, Mifflin Company, Boston.

Blank, William (1980). Competency Based Education: Is it Really Better? School Shop, 16 (14) 24-32

Bloom, B. S. (1980). The New Direction and Education

Research Alterables, Phi Delta kappan. 10 (4), 15-25.

Carrol, J. B. (1963). A Model of School Learning. Teachers

College Record. 64:723 - 733.

Gagne, N. L. (1978). The Scientific Basis of the Art of Teaching. New York: Teachers College Press.

Gagne, R. M. (1967). The Conditions of Learning. New York: Holt Rinchart and Winston.

Kerman, F. S. (1974). The Keller Plan Book, Monlo Park, W. A. Benjamin, Calif. Instructional Science, Theories of Learning and Instruction. The $63^{\text {rd }}$ Year Book of the National Society for the Study of Education. (1) 371-104. Kerman, S. (1979). Teachers Expectations and Student Achievement. Phi Delta Kappan: 6 (4) 30 - 40. 
Improvement of the Teaching of Vocational Ed....

Linblom, C. E. \& Cohen, D. K. (1979). Usable Knowledge, Yale: University Press.

Lumsdaine, A. A. (1964). Educational Technology, Programmed Instruction and Instructional Science, Theories of Learning and Instruction. The $63^{\text {rd }}$ Year Book of the National Society for the Study of Education. (1), 104-171.

McNeil, J. D. (1982). A Scientific Approach to Supervision. Edited by T. J. Sergiovanni. Supervision of Teaching. Alexander: Association for Supervision and Curriculum Development. 30(1), 18-34.

Medley, D. M. (1979). The Effectiveness of Teachers Calif: Mc Cutchhan Pub. Co.

Mekeachie, W. J. (1974). The Decline and Fall of the Laws of Learning. Educational Researcher, 3(1), 2-11.

Prophy, J. E. \& Evertson, C. M. (1994). Process Product Correlation: Texas Teacher Effectiveness Study. Austin: University of Texas.

Rosinshin, B. V. (1977). Academic Engaged Time, ContentCovered, and Direct Instruction: A Paper presented at AERA, New York.

Sergiovanni, T. J. (1982). Towards a Theory of Supervision Practice: Integrating Scientific, Clinical and Artistic Views. Edited by T. J. Sergiovanni. Supervision and Curriculum Development. 31(1), 70-75. 